\title{
EDITORIAL Imagens da prostituição
}

"A literatura assume muitos saberes, [...] ela é a realidade, isto é, o próprio fulgor do real [...] faz girar os saberes, não fixa, não fetichiza nenhum deles; ela lhes dá um lugar indireto, e esse indireto é precioso", afirma Barthes (2013: 18-19) em sua notável Aula, de 1977. Em consonância à ideia que desenvolve, o crítico redefine a etimologia de sapientia, ao afirmar não ter esta "nenhum poder, um pouco de saber, um pouco de sabedoria, e o máximo de sabor possível”.

Ora, quanto sabor não podemos encontrar em figuras como Fronésia, Bacchis, Manon Lescaut, Marthe, Juliette, Marguerite Gautier, Nana, Marcela, Lucíola, Christina F. - só para citar algumas que nos vêm à memória de relance? As aventuras dessas horizontales, como um dia pejorativamente foram chamadas, não deixaram de encantar gerações de leitores ao longo dos séculos.

Há muito as meninas adentraram a literatura e ali, às vezes de modo indireto, provocaram, encantaram, fizeram girar seus saberes e, no recontar de suas próprias vidas, tornaram-se elas mesmas fetiches de hordas de leitores. Tomemos por exemplo, Fronésia, já envolta na poeira do tempo, mas que em $O$ Truculento, de Plauto, é objeto da paixão de nada mais nada menos que três rapazes, dos quais subverte grandes somas de dinheiro, afirmando a existência de uma criança nascida de seus amores. 
Não por outra razão, na literatura, à prostituta atribuiu-se o status de mulher fatal: livre e independente, era temida pela burguesia porque nas vezes em que se aproximava do homem, visava sua parte mais sensível, o bolso. Mas isso era um medo burguês! A prostituta, ou melhor, a noção de prostituta extravasa, vai além, épolissêmica: frequentemente associada às fantasias masculinas e/ou descrita de modo caricato, no espaço textual as definições atribuídas a ela se anulam e, malgrado estilos e gêneros, o que se tem são representações que variam entre dois extremos: a luxúria ou a miséria, a cobiça ou a abnegação, a inocência profanada ou a libertinagem assumida, a escrava sexual ou a mulher fruindo com liberdade de suas escolhas (SÉRY, 2013: 1).

Não à toa, a prostituta adentra o estético, cujo valor é uma preocupação de ordem pessoal. Talvez por isso Baudelaire venha na contramão do clichê que ao amor o Romantismo arroga a si e proclama: "O amor é o gosto da prostituição" (1937: 249-250). Ora, se o valor estético se particulariza na esfera individual e não na social, a ponto de não poder ser reconhecido, experimentado e/ou transmitido aos incapazes de apreender suas sensações (BLOOM, 2010: 30), por que então não falar dessa personagem que perturba, transtorna e subverte a ordem social e, ainda assim, conquista status artístico?

Na literatura, a prostituta goza de aura diversa, prolixa: ora predadora ora presa, desliza pelas entrelinhas, cruza épocas, sociedades e histórias, afirma-se em diferentes aventuras e dramas; acantonada pela sociedade, é tomada por arrivista; invejada por ser livre, é vista como dissidente moral, torna-se alvo de puritanos e é vítima de preconceitos. Mas, ainda assim, permanece, e cada uma delas escreve sua própria história face à sociedade que lhes oprime.

Essas histórias, diga-se, arrastam-se pelo tempo e fazem dessa personagem grande protagonista literária. Tome-se, por exemplo, Pippa, que saiu da pena do hedonista italiano, Pietro Aretino (Les Ragionamenti). Em um desses Ragionamenti,Aretino traz à cena duas prostitutas: Antônia e Nanna, esta última, já aposentada. As duas mulheres discutem o futuro de Pippa, de 16 anos, filha de Nanna. Três saídas são consideradas: religião, casamento ou prostituição: "Ao fazê-la uma cortesã - o mundo sendo tão podre - de pronto, você arrisca fazer dela uma dama; e com o que você ganha e o que ela ganhará, rapidamente ela se tornará uma rainha”.Antônia resolve a questão. "Minha opinião é que você faça de sua Pippa uma prostituta;porque a freira trai seus votos, a mulher casada mata o sacramento do casamento, mas a prostituta não engana nem o mosteiro nem o marido. [...] Decisão tomada, Nanna instrui Pippa na arte da puttanesca”.

Os anos passam e a prostituição tornar-se-á algo emblemático na esfera dos movimentos naturalista e realista, mas também decadentista e simbolista, de modo a ilustrar a prostituta orbitando em diferentes hierarquias e espaços: das calçadas, aos cabarés; das lorettes às cortesãs frequentadas por influentes da sociedade e da política. Balzac, Flaubert, Dumas filho, os irmãos Goncourt, Zola, Huysmans, Octave Mirbeau, Léon Bloy, Jean Lorrain, Maupassant e até mesmo Jean Genet 
que, em Journal d'un voleur, conta seus dias de vagabundagem e prostituição pelas ruas de Barcelona no início do século XX.Mas o sabor dessas aventuras não para por aí: mal começamos o século XXI e Michel Houellebecq causa polêmica com seu Plateforme! As filles de joie têm muito mais a nos contar, por isso, esse dossiê dedicado à prostituição na literatura.

Nossonúmero, dedicado ao tema As Faces da Prostituição na Literatura de língua francesa, abre-se com a contribuição de Israel Victor de Melo, discorrendo justamente a respeito da prostituição e das relações sociais de poder em Houellebecq, através das figurações da figura da prostituta e de seus contratantes em seu texto "Prostituição e relações sociais de poder em Michel Houellebecq". Também opondo dois pólos da sexualidade dita imoral, mas se concentrando na diferenciação entre a prostituta e a adúltera, Soumaïla Traoré, doutorando da Costa do Marfim, em "Entre vice et vertu: le double visage de la courtisane dans l'oeuvre d'Alexandre Dumas fils", analisa essas duas imagens conforme são contrapostas em A Dama das Camélias e Le roman d'une femme.

Este dossiê também conta com a especial contribuição de diversos autores do continente africano, abordando a questão da prostituição sob um viés ora póscolonial, ora político e econômico voltado a questões internas a partir de um corpus variado de expressão francesa. O senegalês Yves Diouf analisa o aumento da prostituição como meio de subsistência após a perda de tradições locais em seu artigo "Formes et enjeux de la prostitution dans Le Sous-préfet de Mosé Chimoun". Na mesma linha, em "Le personnage-prostitué dans quatre romans contemporains”, o professor camaronês Bernard Bienvenu Nankeau analisa a figura do prostituto a partir de seu lugar na sociedade, dando ênfase à questão psicológica, somada ao incontornável aspecto moral, conforme quatro categorias: o concumbino, o libertino, l'absentéiste e o jovem de rua "exótico", nos romances L'Immeuble Yacoubian, de Alaa El Awany, Place des fêtes, de Sami Tchak, Ève de ses décombres, de Ananda Dévi, e La chair du maître, de Dany Laferrière. Já em "La mauvaise parole chez Choukri : d'un aspect linguistique a un aspect erotique", o marroquino El Arbi El Bakkali envereda para uma análise da obra autobiográfica de Mohamed Choukri, utilizando-se de uma abordagem linguística para discutir o teor erótico dos insultos contidos em duas obras do autor.

Com uma forte abordagem pós-colonial, as argelinas Sihem Guettafi e Wassila Soltani, no artigo "Prostitution coloniale et nationalisme: collaboration corporelle dans Ciel de Porphyre de Aicha Lemsine" discutem a prostituição como forma de dominação colonial e seu desempenho durante as guerras de libertação na Argélia, tecendo importante relação entre história recente e literatura contemporânea.

Encerrando o dossiê, Dirceu Magri nos traz a tradução comentada do conto “As Lápides”, de Guy de Maupassant, sobre uma mulher que busca amantes em cemitérios, de modo a apresentar prostituta e prostituição como espelhos refletindo a hipocrisia burguesa: adequadas, não inconvenientes! 
Para além do eixo temático, na seção de literatura, Melissa Raquel Zanetti Franchi discute em seu artigo "O escritor, o capital e a sociedade de aparências em A Musa do Departamento" a hipocrisia burguesa em oposição ao romantismo, a partir da análise do protagonista balzaquiano, um boêmio literato.

Já o artigo "Parcours, auteurs et sujets migrants : Fatou Diome et Abdourahman Waberi”, de Konan Arsène Kanga, também professor na Costa do Marfim, dedica-se à questão da migração na obra metaficcional dos dois autores mencionados no título do trabalho.Encerrando a seção, o estudo "Referentialisation chronotopique et gestion des temps nouveaux dans L'A-fric de J.F. Ndongo"do camaronês Pierre Suzanne Eyenga Onana investiga o correlato do espaço-tempo na criação de um mundo novo na trama romanesca apontada no título.

Por fim, na seção de linguística, o artigo "Termos da gastronomia francesa utilizados na gastronomia brasileira na categoria dos molhos", de Anabel Soares Batalha e Rita Maria Ribeiro Bessa, traz um interessante estudo terminológico baseado em recolhimento de corpus e análise contrastiva dos termos gastronômicos, em português e francês.

Assim, com contribuições de seis diferentes países, trazendo no presente número uma grande diversidade de abordagens, perspectivas, teóricas, autores e seus respectivos objetos de análises, fazemos votos de uma excelente leitura.

\section{Ana Carolina Lazzari Chiovatto e Dirceu Magri, Editores do número 11}

\section{BIBLIOGRAFIA}

ARÉTIN, Pierre. La vie des courtisanes. Paris : Éditions Allia, 1996, p. 123.

BARTHES, Roland. Aula: aula inaugural da cadeira de semiologia do Colégio de França, literária pronunciada dia 7 de janeiro de 1977. Tradução e posfácio: Leyla Perrone-Moisés. São Paulo: Cultrix, 2013.

BAUDELAIRE, Charles. Oeuvres complètes de Charles Baudelaire. Fusées. Paris : Éditions de la Nouvelle Revue Française, 1937.

BLOOM, Harold. O Canône ocidental. Tradução: Marcos Santarrita. Rio de Janeiro: Objetiva, 2010.

SÉRY, Macha. La prostitution à travers les arts : la littérature (chapitre 5). Le Monde, o3 de dezembro de 2013. Disponível em: https://goo.gl/pzJo7Z. Consultado em 14 de dezembro de 2017. 